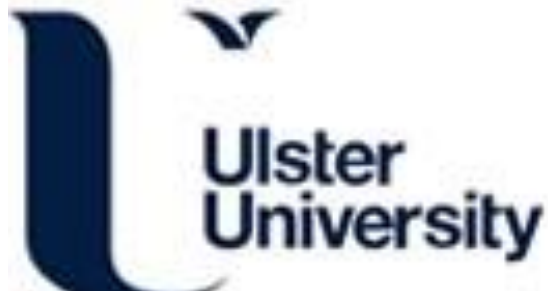

\section{A multifaceted approach to building capacity for marine/maritime spatial planning based on European experience}

Ansong, J., Calado, H., \& Gilliland, P. M. (2019). A multifaceted approach to building capacity for marine/maritime spatial planning based on European experience. Marine Policy, 132, 103422. https://doi.org/10.1016/j.marpol.2019.01.011

Link to publication record in Ulster University Research Portal

Published in:
Marine Policy

Publication Status:

Published (in print/issue): 07/02/2019

DOI:

10.1016/j.marpol.2019.01.011

Document Version

Author Accepted version

\section{General rights}

Copyright for the publications made accessible via Ulster University's Research Portal is retained by the author(s) and / or other copyright owners and it is a condition of accessing these publications that users recognise and abide by the legal requirements associated with these rights.

\section{Take down policy}

The Research Portal is Ulster University's institutional repository that provides access to Ulster's research outputs. Every effort has been made to ensure that content in the Research Portal does not infringe any person's rights, or applicable UK laws. If you discover content in the Research Portal that you believe breaches copyright or violates any law, please contact pure-support@ulster.ac.uk. 


\begin{abstract}
Over the past decade, marine/maritime spatial planning (MSP) has matured from a concept to a practical approach in advancing sustainable development and management of marine space [1]. However, MSP still remains a relatively novel and complex process which involves various disciplines, procedures and engagement with multiple interests within differing governance arrangements and legal settings at different spatial scales in a dynamic system. MSP, therefore, requires marine planning practitioners and their institutions to be adequately equipped to address all of these and emerging challenges. Europe has invested in capacity building for MSP over the years with the adoption of the MSP Directive [2] being the main driver for implementation in some Member States alongside those where MSP had already been initiated. This paper provides an overview of experience, practical challenges, and lessons learnt from capacity building initiatives to do with education and training courses, establishing a national planning body, and cross-border projects, mainly from Europe. The paper broadly considers the skills, training and knowledge required for the MSP process. It stresses the importance of developing capacity at all levels, prioritising resources for capacity building and ensuring effective partnerships between the different actors and institutions. Finally, recommendations, potential next steps and priorities are suggested for furthering MSP capacity building.
\end{abstract}

\title{
Keywords
}

Marine spatial planning, Capacity building, Skills, Education, Training, Transdisciplinary

\section{Introduction}

Marine or maritime spatial planning (MSP) remains a complex and challenging process despite experience gained over the last decade. The process involves multilevel interaction with multiple sectors and stakeholders at various governmental levels (the division of power between central and local governments), spatial scales (local, national, transnational), with varying legislation and approaches in decision making to determine the organisation of human activities in marine space [[3], [4], [5]]. Well-trained professionals and robust institutional frameworks for the implementation of this novel and complex process has become increasingly important.

Previously the study and management of the ocean often took place within individual disciplines focussed on specific issues or sectors independent of other disciplines and issues [6,7]. MSP has been influenced by many of these disciplines such as ecological science, physical planning, natural resource management and conservation [[8], [9], [10]]. Delivery of 
the MSP process requires the contribution of professionals from diverse backgrounds including from ecology, oceanography, social and anthropological sciences, economics, law, governance and public policy-making $[\underline{11}, \underline{12}]$. However, it is essential that there are synergies between these to respond to the transdisciplinary and complex nature of MSP. Therefore, education, training and institutional arrangements to implement MSP must consider and address the need to work across disciplines in a 'holistic' way [13].

The first established example of MSP, in the Great Barrier Reef Marine Park (Australia) in the 1980s, was in support of the objective to address marine environmental degradation due to human activities and natural processes $[\underline{14}, \underline{15}]$. In Europe, early developers of MSP such as Germany, the UK, Belgium and the Netherlands were generally responding to new emerging uses such as offshore wind and the need to manage current and future competing uses [16]. Subsequently, in Europe, the adoption of the MSP Directive [2] has been a key driver for building capacity for MSP in most Member States alongside those where MSP had already been initiated. Recent studies suggest there has been a paradigm shift in MSP from an environmental focus and managing conflict among uses to a more holistic approach for coordinating sectoral policies, facilitating transboundary cooperation and optimising planning advantages $[1,17]$. For MSP to continue to evolve and respond to changing drivers, legislation, and policy, it needs to be adaptive and capacity building must be an integral part of that.

Capacity building involves the development of individual and institutional resources within a favourable policy context in response to emerging needs [18]. It also has to involve broader systems and networks of various actors, organisations and institutions [19].

Capacity building in relation to MSP can be defined as the process through which the abilities of individuals, institutions and their networks are developed and enhanced to make effective and sustainable decisions about the temporal and spatial ordering of human activities in the marine space.

It is important that individuals are trained and educated in MSP to improve their skills, knowledge and behaviours in support of a successful MSP process. Institutions, especially those with a remit for MSP and others that need to contribute to the process, need operational capabilities including to effectively coordinate with and between stakeholders, different sectors, and transboundary institutions. Capacity building in MSP is required at all levels and should strengthen legal, administrative, financial, technical, and human resource to address various multifaceted issues that make the MSP process complex (See Fig. 1). 


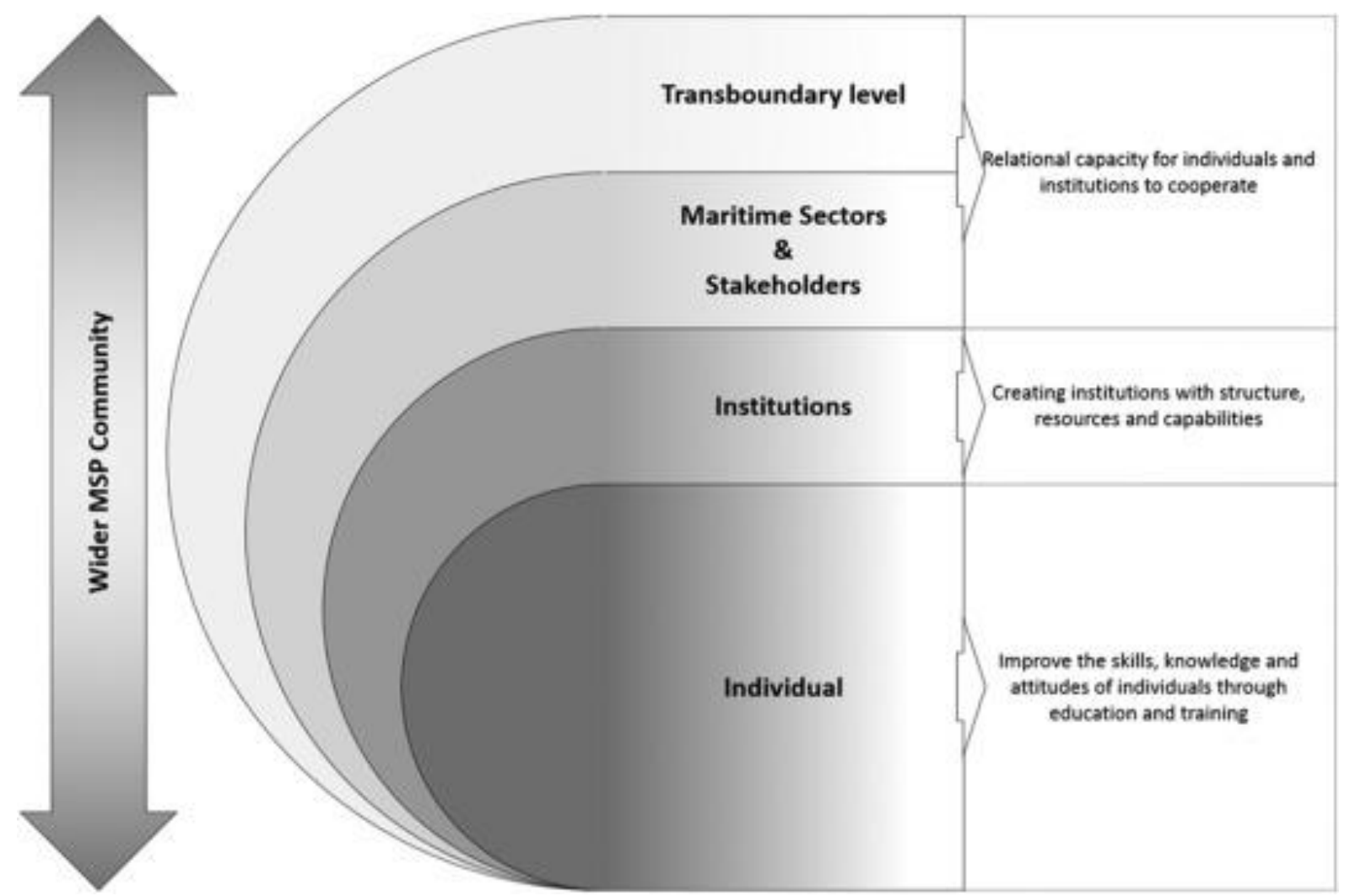

Fig. 1. Multifaceted Approach to Building Capacity for MSP. Adapted based on [20].

A number of assessments of MSP capacity building have been undertaken, mainly to determine: skills and support needed for MSP professionals [21], core content of MSP education/training $[\underline{13}, \underline{22}]$, capacity needs for effective stakeholder engagement $[\underline{23}]$ and others initiated by MSP authorities before recruiting marine planners. Results and recommendations from these efforts show that there is an urgent need for MSP professionals to have a broad skill set and knowledge that goes beyond 'traditional' disciplines to include an understanding of legal frameworks, programme management, and the ability to work in inter-disciplinary teams. MSP education/training was also identified to be essential for professionals from the full range of maritime and coastal sectors. Case studies of real-life MSP examples, peer to peer mentoring and knowledge transfer were identified as models for training professionals [21,24].

The following sections explore a multifaceted approach to building capacity for MSP by reviewing the experience of capacity building initiatives in education and training courses, a national planning body and cross-border consortia and projects, mainly in Europe. Practical challenges and recommendations are then summarised to serve as lessons for other initiatives and furthering MSP capacity building. 


\section{Materials and methods}

This paper combined various methods and materials in reviewing the experiences of the various capacity building initiatives in Europe. The method used to review existing MSP educational materials and training courses was based on online research of key words in English including: Marine Spatial Planning Courses, Maritime Spatial Planning Courses, and alternatives to "Courses" such as "Degree", "Master", "Phd" "summer Course" and "training school". In each situation, the same method was used but words such as "management" or "planning" were specified for searching courses or training in Marine Biology, Oceanography, Fisheries, Shipping, Port Management, and Marine/maritime studies. The first search was Google-based followed by a 'snowball' approach to other online search engines such as Bing and Yahoo. The search focused on academic or learning/training experiences for the past five years in Europe. The list of courses obtained was then screened for contents and entry requirements. The resulting data and selected material were collated into Microsoft Excel and have been presented in charts on various themes including the words in the title of the courses (see Fig. 2).

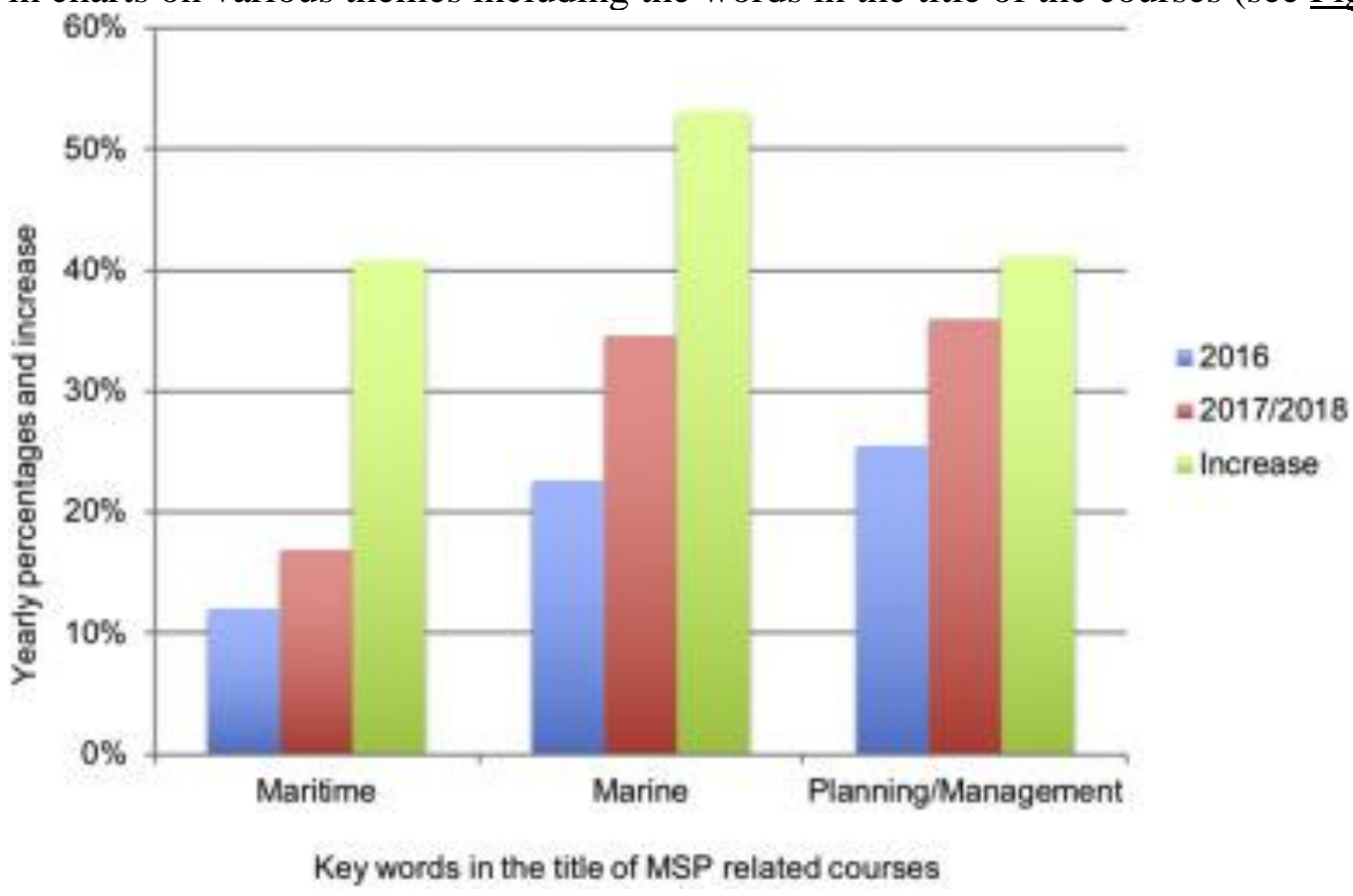

Fig. 2. Differences between wording of MSP related courses in 2016 and 2017/2018.

Cross border MSP experience in Europe was based on an independent analysis of cross border MSP projects that were implemented between 2009 and 2014. Project documents were reviewed, and interviews were conducted with at least one partner institution in each project including research, academia and national agency. The capacity building at the operational and institutional level is mainly based on the direct involvement and views of one of the authors in England's MSP process at the Marine Management Organisation (MMO), the government 
agency delegated to prepare marine plans and might not necessarily reflect the views of the MMO. The recommendations for MSP capacity building are based on the results of the review and the authors long-standing experience in MSP education and training, MSP implementation at the operational level and through cross border MSP projects in Europe.

\section{Review of MSP capacity building initiatives}

The following section provides an overview, based on the methods and material set out above, of capacity building materials, experience and trends to understand the challenges and differences between MSP theory and its practical application.

\subsection{MSP education and training}

Priority area 4 of the "Joint Roadmap to accelerate Maritime/Marine Spatial Planning processes worldwide" [25] is devoted to 'Capacity Building' with two major actions identified: training for planners and pilot projects to build capacity for MSP. This sub-section provides an overview of recent experience and existing educational resources focused on pedagogic/educational material.

\subsubsection{Existing pedagogic/educational material}

For the purpose of this paper, material such as videos are not addressed, although some of them, e.g. "What is marine planning?" [26], are important for public awareness. Since the early stages of the MSP debate in Europe, the Intergovernmental Oceanographic Commission (IOC) of UNESCO has supported the educational dimension of capacity building, particularly through its web platform, sharing experiences from all over the world, and the publication of the widely-used manual, "Marine Spatial Planning: A Step-by-Step Approach toward Ecosystem-based Management" [27], complemented by "A guide to Evaluating Marine Spatial Plans” [28].

The "Step-by-Step Approach" provides a clearly-organized process intended to guide practitioners but it has also been used to promote and guide classroom debates and to structure analysis, especially within audiences with previous knowledge of spatial planning. For less experienced audiences, the cartoon "Become a Maritime Spatialist within 10 min" [29] provides clear informative messages on MSP and the cartoon "How to safeguard the seas with ecosystem-based management" [30] conveys a clear method to promote discussion about applying such an approach in MSP. 
World Wide Web platforms have become a common teaching resource [31], e.g. the IOCUNESCO MSP website ${ }^{1}$ offers information on MSP case studies and an important teaching material for comparative analysis. The European MSP Platform ${ }^{2}$ provides in depth information on specific aspects of MSP and complementary information on the processes and projects within EU Member States. OpenChannels ${ }^{3}$ is another important platform for disseminating information on MSP initiatives, tools and literature, as well as promoting and supporting debate.

Case study analysis and comparative analysis are within the methods of the "case-teaching approach" presented by the Harvard Business School and an important method for MSP training. "Lessons learnt from the practice of Marine Spatial Planning: teaching case studies" [24] provides a very useful teaching material on MSP.

\subsubsection{Educational experiences}

A study by Gissi and Vivero [13], in the context of the Erasmus Mundus Master Course on Maritime Spatial Planning (EMMCMSP), ${ }^{4}$ analysed the existing educational provisions for MSP, identifying a multiplicity of combinations on contents and methods. In their conclusions they highlighted that MSP encompasses a wide range of science themes which may be increased by the continuing multiple interpretations of what constitutes and defines MSP.

Applying the same rationale as Gissi and Vivero [13] to initiatives for 2017/2018 adds 26 programmes/courses to the 51 they reviewed. The additional numbers are mainly due to the appearance of more training courses, short courses and degrees on marine sciences. The number of degrees specifically on MSP remains almost the same with only one additional initiative identified in the UK, making it the country with most degrees (three) on MSP. The analysis of the $2017 / 2018$ period shows that there is a marginal shift towards including the planning/management process and practice into the core of MSP education and training (see Fig. 2).

The use of the term "Maritime" (assuming human uses) as against "Marine" brings some differences to the 2016 study. While in 2016, circa $12 \%$ of the educational initiatives used the title word "Maritime" (against 22.6\% with the word "Marine"), on the updated analysis this has increased to $16.9 \%$ (against $34.6 \%$ using "Marine"). The more evident change in educational experience in MSP is the fact that circa $36 \%$ of the initiatives used the words

\footnotetext{
${ }^{1}$ http://msp.ioc-unesco.org/ [accessed 31.01.2018]

${ }^{2}$ http://msp-platform.eu/ [accessed 31.01.2018]

${ }^{3}$ https://www.openchannels.org/ [accessed 31.01.2018]

${ }^{4}$ http://www.iuav.it/Didattica1/master/master---I1/Erasmus-Mu/ [accessed 31.01.2018]
} 
Planning and/or Management in their title, as compared to only $25.5 \%$ in 2016. This suggest practical aspects are becoming more central to teaching on MSP.

The EMMCMSP is the main European effort to disseminate MSP education within and outside Europe as it targets students across the world. Apart from that, projects such as the Strategic Partnership for MSP (SPMSP) ${ }^{5}$ funded under Erasmus+ is also developing a common European educational agenda and promoting transnational cooperation of experts in research and practice to overcome isolated individual schemes on current MSP training and education. The EU together with IOC-UNESCO seem to be the main international actors in MSP educational capacity building. For example, initiatives such as "Planning in a liquid world with tropical stakes: solutions from an EU-Africa-Brazil perspective" (PADDLE), ${ }^{6}$ create a collaborative platform for exchange of educational methods and teaching experiences between researchers and actors from other parts of the world and from the European Union.

At a national level, it should be noted that some public administrations have also held internal training for their staff working on or contributing to MSP in government-led initiatives, such as in Poland and in the UK (MMO, Welsh Government).

\subsection{Operational/institutional capacity building for MSP}

There are a range of institutions for and with an interest in MSP at a national level, but this section focuses on those tasked to lead or deliver MSP, sometimes through legislation. The section briefly reviews how MSP authorities have been set up in Europe and the associated operational capacity building. It focuses in particular on England and the example of the MMO based on one of the authors' long-standing experience and involvement in the MMO MSP process.

\subsubsection{Existing maritime planning authorities in Europe}

In many cases across Europe, the MSP delivery role is given to an 'agency' with policy oversight from a relevant government department or ministry. A decision has to be made whether to give the MSP remit to an existing institution or establish a new one. About twentythree coastal EU Member States have set up competent authorities for MSP so far [32]. Many of these have assigned the MSP role to an existing agency at the national level e. g. in the case of Federal Maritime and Hydrographic Agency for the EEZ in Germany [33]. Such agencies normally work as the 'lead' with support from other technical agencies or through an interdepartmental/ministerial coordination team as is the case in Ireland and the Netherlands

\footnotetext{
${ }^{5}$ https://sp-msp.uol.de/ [accessed 17.10.2018]

${ }^{6}$ https://www-iuem.univ-brest.fr/paddle/project/presentation [accessed 31.01.2018]
} 
$[34,35]$. In some countries, a new body is created at national/regional level e.g. Marine Scotland and the Marine Planning Partnerships respectively in Scotland [ㅎ6].

\subsubsection{Experience from England - the MMO}

In England, it was concluded [37] that the cross-cutting nature of MSP required a new body to be set up, partly as existing agencies all had a focus on one aspect of sustainable development or on particular sectors/interests. The Marine and Coastal Access Act [38], made provision for a new marine planning system and a new body, the MMO. Importantly, although the MMO is a body that sits under the Department for Environment, Food and Rural Affairs (which tends to lead on wider marine management matters) it also has oversight from other relevant government departments with a policy interest such as defence, energy, land planning and transport.

From 2010, a dedicated marine planning team was set up supported by other MMO teams, for example on data management, evidence gathering and communications. There was no pool of experienced marine planners to draw from other than those in the few countries where MSP was already in place and such specialists would have been unfamiliar with the MSP context in England. Instead, informed by previous capacity analysis, a starting set of skills/competencies and disciplines necessary to undertake MSP effectively was defined and used to guide recruitment (see Table 1). The MMO also consciously sought staff with a range of backgrounds or sectoral knowledge rather than all being drawn from, for example, environmental specialist. This also made for a 'rounded' perspective in the team which mirrored the range of interests and views of external actors (see Table 1, represented by staff recruited during the first two years of the MMO). Inevitably not all disciplines or areas of expertise could be represented with one team, for example in social science or socio-economics; initially input was provided through 'loan' from a specialist in the government department, but generally such expertise has been commissioned when needed through contracts.

Table 1. 'Menu' of skills/competencies and expertise/backgrounds to consider in initial design of a marine planning function or body based on authors participation and experience in the MMO MSP process.

\section{Skills and competencies}

-Thinking strategically Communicating effectively

-Analysis and judgment

-Objective decision-making

\section{Expertise and backgrounds}

-Marine scientists and technical specialists e.g., oceanographers, ecologists, surveyors -Economist, geographers, political scientists

- GIS, data and IT specialists

-Legal and policy expertise 


\section{Skills and competencies}

-Project management

process/change management

-Stakeholder management

engagement

-Policy and decision-making

-Analytical/research \& problem-solving

skills

-Facilitation

-Negotiation and mediating

\section{Expertise and backgrounds}

and $\cdot$ Terrestrial planning

-Sectoral interests such as fisheries and marine industries

and $\cdot$ Environmental interests

- Heritage and cultural interests

-Growth strategies, regeneration and economics

-Sustainability Appraisal

The staff brought in became 'marine planners' through practice and application of their particular expertise. This has been assisted by involving all staff in the different stages of the planning process in some way and in stakeholder engagement, e.g. facilitators at large multiinterest workshops.

The planning function grew from a 'start up' team of six in 2010 to six to around seventeen by 2014 to almost thirty from 2016 onwards. That has been in response to an increasing portfolio of work, both in the number of plans being prepared at any one time and the need to implement and monitor published plans alongside those in development. The staff are distributed across a 'core' team largely based in the MMO's headquarters and one or two local officers in the each of the marine plan areas. Inevitably, over such a period of time the team has been through several iterations and seen turnover of staff. In response, the capability has been maintained and grown through various means, e.g., desk notes recording how particular tasks have been approached or delivered with lessons learned for successive staff to refer to when approaching the same tasks in subsequent planning processes.

\subsubsection{Capacity building across other institutions and the 'wider MSP community'}

Experience from practice shows that MSP capacity extends well beyond any dedicated MSP authority to encompass what might be considered the wider 'MSP community' (see Fig. 1). This develops partly through relevant sectoral institutions and interests reacting to the planning process and allocating lead staff, e.g. some organisations such as The Crown Estate in the UK and Historic England have positions with the title 'head of' or 'lead' on marine planning. The development of an 'MSP Community' can also be achieved through proactive initiatives such as academia establishing relevant courses and consultancies growing or adapting their capability $[\underline{13}, \underline{31}]$ and other initiatives to build cooperation among these MSP institutions.

\subsection{Capacity building through cross-border MSP projects and consortia}


This section focuses on the international level which involves a range of interests including academia, government agencies, consultancies, international organisations, industry,

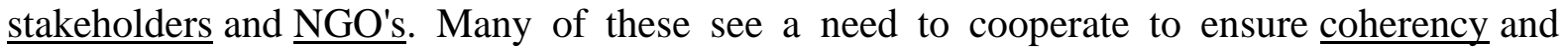
effective implementation of MSP while respecting that competence for MSP lies with individual countries, e.g. Member States in the European Union. In Europe, the relational/network dimension of capacity building for MSP has mainly been undertaken through cross-border consortia/projects where capacity for partnership, effective communication and cooperation between these institutions have considered disciplinary boundaries to share information and tailor common approaches that can be applied in MSP.

\subsubsection{Cross border consortia and projects}

The first series of EU cross-border projects (Plan Bothnia, BaltSeaPlan, ADRIPLAN, MASPNOSE, TPEA and PartiSEApate) took place mainly between 2009 and 2014. The second series (BalticScope, MARSPLAN, SIMCelt, SIMWESTMED, SIMNORAT, SUPREME) were mainly started after the adoption of the MSP Directive in 2014. As some of the second series of projects are still underway at the time of writing, the sub-section below reviews the experience and contributions from the first series of cross-border (see Fig. 3). 


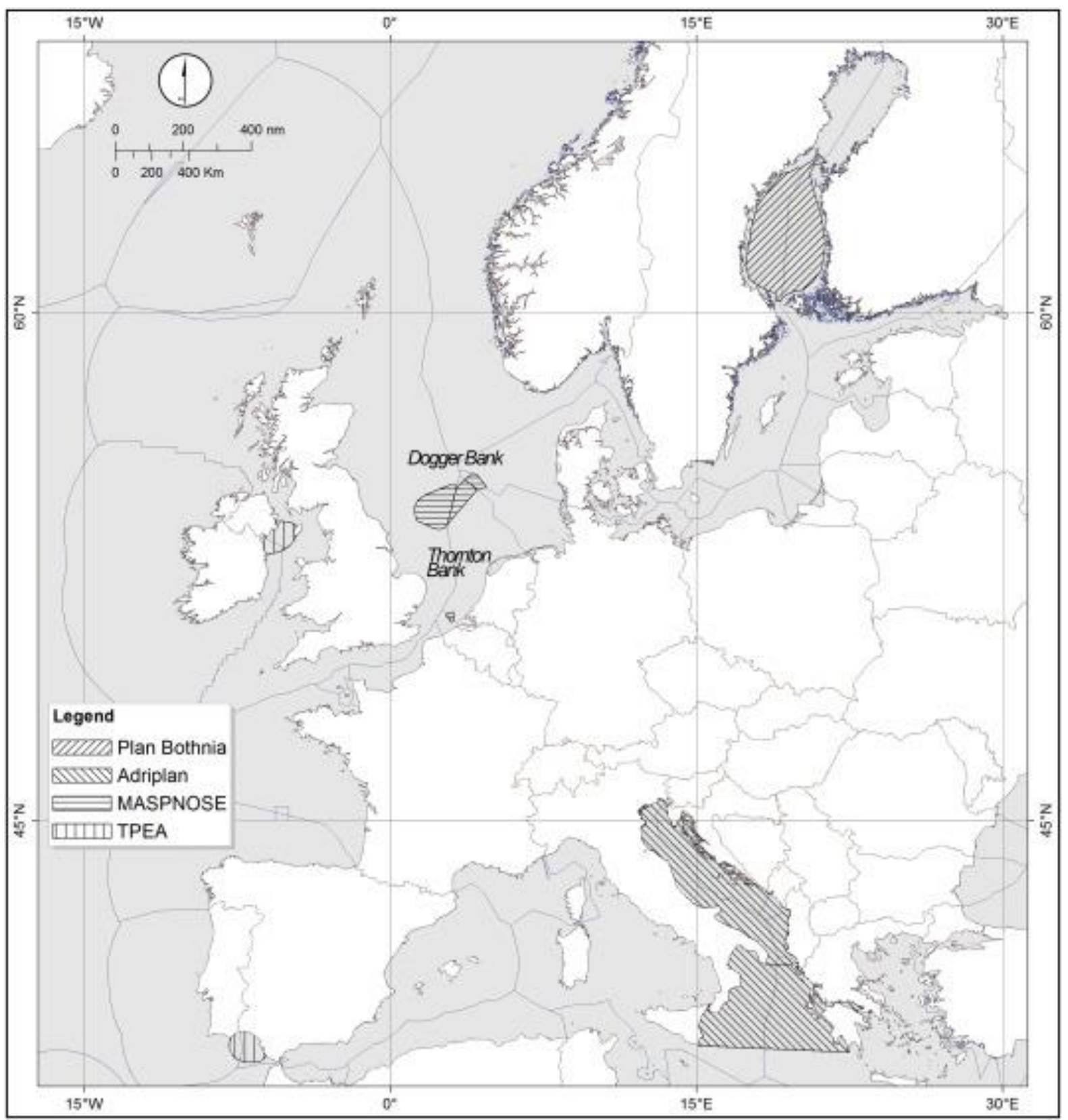

Fig. 3. Distribution of Cross-border MSP projects in Europe. Source: European Atlas of the Sea [39].

\subsubsection{Experience from cross-border projects}

Plan Bothnia was one of the first cross-border projects to test transboundary MSP, generating experience in international cooperation and knowledge of different planning methods and cultures [40]. The output from the pilot project served as an early example for discussion during the formulation of other MSP process and projects, e.g. Finnish MSP legislation and the decision for regional planning by Finnish regional councils. 
The MASPNOSE project included a process focused on the Dogger Bank Natura 2000 site designated by Germany, UK and the Netherlands which enhanced interaction between stakeholders and authorities to develop fisheries management proposals [41]. Through the project, position papers produced by the North Sea Regional Advisory Council (NSRAC), which is a regional membership organisation comprising fisheries interests and stakeholders were used in formal transboundary engagement process and the NSRAC became an observer in the Dogger Bank Steering Group (comprising officials from the three countries). Experience from the Dogger Bank case study was also used in a Dutch Marine Strategy Framework Directive (MSFD) process to find additional areas for seafloor protection (MSFD D6, Seafloor integrity).

The ADRIPLAN project which was the first of its kind in the Mediterranean region, building on existing scientific and research cooperation in the Adriatic, to explore and advance a methodology for MSP implementation in the region [42]. The project also stimulated and provided capacity for exchanging experience, best practice and establishing cooperation among institutions (academic, national and regional governments) for MSP implementation.

The TPEA project considered two pilot areas - the Irish Sea between the UK and Ireland and the border between Portugal and Spain respectively (See Fig. 3) - that provided a 'northern' and 'southern' context to test a commonly agreed approach to cross-border MSP [43]. At the time of the project, countries such as Ireland and Spain had not started MSP, whilst Portugal and the relevant parts of the UK were at early stages of marine plan development. The project served as a first scoping approach to test cross-border MSP in the Eastern Atlantic. The partners in the 'southern' pilot had relatively more expertise in data management and geographic information system (GIS) whereas those in the 'northern' pilot focused more on the stakeholder aspects of MSP. The exchange of knowledge and expertise between partners from within and across the two pilot areas contributed learning to support national MSP processes.

\section{Discussion}

Capacity building is required across a range of interests and institutions and at different levels (national, regional and international). It also requires attention to education and training, the wider MSP community and meeting the transdisciplinary nature of MSP. The following section considers all of these under three topics of discussion drawing on the different perspectives set out in Section 3 . 


\subsection{Gaps and challenges to building capacity for the wider MSP community}

There are a range of challenges that apply irrespective of whether they are faced in MSP education for individual institutions or the wider MSP community. An overarching challenge is that capacity needs to be developed across a range of institutions, from a dedicated planning body to other contributing partners, across interested parties and stakeholders e.g. developers and their consultants, $\underline{\text { NGOs, }}$, and in the wider community, e.g. through networks and coastal fora. Inevitably, this takes time and resources and may require priority setting.

A specific challenge is the transdisciplinary nature of MSP, the complexity and size of the task, and inevitable limitations in resources to respond to these. MSP is generally well-established within in the environmental management community but there remain gaps, e.g. the involvement of social scientists and provision of socio-economic expertise. This is illustrated by the various MSP programmes which have limited specific socio-economic course content/modules [13]. Finally, being able to synthesise different knowledge and information to develop and implement MSP is a major challenge. The skills, material and logistics to enable marine spatial planners to undertake this task need to be included in training and developed by relevant institutions.

While the focus of any designated planning body is to prepare and implement marine plans, they also have a role in facilitating and fostering the development of a wider capability and establishing a marine planning discipline. In practice, this is challenging within the constraints of needing to focus on their main role. Instead, many of the efforts to engage in the wider community, particularly at a transboundary level in Europe, have been driven by the EU as shown through the review of cross-border projects.

Whilst there are numerous peer reviewed articles on the experience of MSP in Europe, there remains a gap in contributions from the planning authorities or bodies themselves. There is also probably a need for greater input from those actually undertaking MSP and leading plan development in the design of MSP training and courses. Analysis of the first series of crossborder consortia showed that they mostly comprised academic, research institutions with less planning authorities involved. Although more planning authorities are involved in the second series, it is important that these consortia involve relevant authorities and sectoral agencies engaged in MSP at an operational level. That would help to ensure that the insights and recommendations from these projects are more transferable to statutory MSP processes. 


\subsection{MSP theory compared to the reality of MSP practice}

Although the MSP degrees delivered by higher education institutions in Europe encompass a wide range of disciplines, legal frameworks and governance, the operational application of MSP has been mainly through hands-on planning workshops or comparative analysis of plans. It is necessary to realise that in practice, the governance framework and resulting approach to MSP is specific to each jurisdiction and that variation cannot be fully covered in any one MSP course. But there are common requirements, such as engagement, negotiation and conflict management skills, which is important to develop through MSP training and education.

In some countries such as the UK, the MSP process began before tailor-made MSP courses had been established. Therefore, there were no 'trained' marine planners to allow a comparison between theory and practice. That is changing and recent experience suggests there may be a gap in teaching about how plans are implemented once prepared. That said, the reality will always be context specific and there is only so much a general course can cover unless it is explicitly linked to the planning process in a particular country or region as shown in the Baltic University Programme on MSP [44]. It also appears that courses that include some form of internship or work placement with an MSP authority e.g. EMMCMSP, provide the student with a better understanding of applied practice, e.g. with respect to stakeholder engagement. The reality of borders should always be respected in the study and piloting of cross-border MSP. International capacity initiatives should consider that capacity needs, whether technical, legal, financial, or other, vary across borders. Where needed, institutional or individual support should be tailored to different capacity needs through exchange of technical knowledge and expertise between partners.

\subsection{Good practices on capacity building from the various initiatives and experiences}

In an effort to balance MSP theory and practice, the EMMCMSP at first focused on the theoretical aspects and the consolidation of concepts on MSP. Through continuous assessment, the course content was adapted over time, shifting to a more practical and operational approach to teaching such as hands-on planning workshops and an emphasis on learning from practice and case/pilot studies. There is also much to be learnt from the experiences of the cross-border MSP projects and planning authorities which can be brought into MSP training and courses. The MMO, for example, have provided talks and informal training to university courses, networks, and professional bodies and have regularly hosted students on work placement/experience. 
As the MMO planning function developed over time, the staff members became 'marine planners' even though they each retain particular specialism or expertise. This evolution occurred slowly but was probably enhanced by having a 'team' of critical mass rather than simply commissioning in most required input. Additional competencies that had not been emphasised at the start of capacity building became important, in particular the ability to write and edit documents, formulate plan policies and understand digital communication. All of these were addressed through bringing in new staff or 'on the job' development and training. It also became apparent that, as the team moved from working on one plan at a time to several plans, there was a need for more dedicated and experienced programme management capability.

Experience, knowledge and networks developed through cross-border projects have contributed to and influenced new MSP projects, as is the case following the Plan Bothnia and ADRIPLAN Projects. These projects have also sought to facilitate cooperation and exchange of experience amongst sectoral agencies relevant to the implementation of MSP.

\section{Recommendations for capacity building in MSP}

It is critical that a marine spatial planner or team have the competencies to be able to function within the complex environment of MSP. The following are some of the competencies considered necessary based on the MSP activities and experience discussed above (see Table 2).

Table 2. Competencies of a marine planner/team based on MSP process/activities.

\section{MSP Process/Activities}

- Defining/Selecting the planning area

\section{Competences: Skills and Knowledge}

-Existing jurisdictional boundaries, bio regions, dialogue skills,

-Planning process and programme of •Programme/project management, systems thinking and activities

-Visions, Aims and Objectives

-Gathering Evidence/Stock Taking

-Stakeholder Engagement

-Analysis of current and future conditions - issues, spatial conflicts, options/alternatives, scenarios management processes

-Policy Analysis, Logical Framework Analysis

-Data Collection methods, spatial database management, existing governance system

-Stakeholder Engagement Tools, Facilitation, Negotiation skills, communication skills

- GIS skills, Scenario analysis, Sector Assessment, Synthesising information, Spatial Analysis; Socio Economic analysis, Environmental analysis, intuitive reasoning 
MSP Process/Activities

-Development of plan policies/measures

-Plan approval and adoption

-Plan Implementation

-Monitoring and Evaluation

\section{Competences: Skills and Knowledge}

-Existing sectoral policies, activity planning, analysis of existing governance system, writing clearly, consensus building

-Knowledge on policies and legislation

-Project/Organisational management

-Understanding a 'logic model' and indicators; knowledge of existing monitoring programmes

\subsection{Recommendations for teaching and academic community}

MSP education/training should address the transdisciplinary nature of MSP by ensuring that course modules and content cuts across the core attributes of MSP including environmental and socio-economic aspects. Modules such as hands-on workshops, field trips and case studies which emphasise the practical aspect of MSP should be integral to MSP training. Other modules on the statutory and governance aspects of MSP are important to understand laws and regulations governing maritime activities and legal framework and to recognise that MSP is context-specific. The diversification of MSP training and education to include more short courses, webinars, in-house training, workshops and MSP literacy campaign should be encouraged. In general, training on how to analyse "equity" (the distribution of benefits and costs of MSP), training for researchers, reviewers, mentors/teachers would also move MSP ahead.

The role of private sector in supporting MSP education should be explored. Collaboration between universities and the private sector should be established through funding and instituting educational programmes such as $\mathrm{PhD}$ 's which are targeted toward research and private sector needs e.g. the PADDLE project.

Establishing partnerships between academia, practitioners and planning authorities that already have the practical experience in MSP, together with pooling resources in expertise and research, should help in developing integrated and practical course contents.

\subsection{Recommendations for MSP authorities and institutions}

It is important that careful thought is given to the range of skills/competencies, expertise and backgrounds required for a planning 'function'. Any capacity analysis will need to be contextspecific but there are sufficient established MSP processes now that such analysis can be informed by their experience if considered appropriate. It helps the thinking around MSP if 
there are a mix of backgrounds amongst those undertaking the planning process that mirrors some of the range of interests affected by MSP.

It is not a given that the capacity is established in-house, i.e. within the competent planning body. The decision to do so depends on resources, governance/institutional arrangements. Different countries have arrived at different solutions involving a mix of in-house staff, partnering with other agencies and buying in commissioned support. The key is that the relevant skills and expertise are provided in some way. One of the benefits of establishing a reasonable critical mass of in-house staff is that it fosters interactive discussions that better inform an integrated endeavour such as MSP. It also enables the development of a 'corporate' capability that has longevity, continuity and better resilience, but only as long as experience and lessons learned are captured and passed on (to avoid 'corporate memory loss'). Working largely through a dedicated team probably enhances the emergence of staff as 'marine planners' albeit whilst they retain particular technical specialism or sectoral expertise.

\subsection{Recommendations for cross-border working and initiatives}

It is important that cross-border projects/initiatives consider regional and national capacity building needs through involving regional and local actors, administrative sectors and departments in the development and implementation of these projects. Capacity needs (technical and institutional) for MSP varies across countries. Where capacity is uneven across institutions in different jurisdictions, there should be targeted funding and efforts to ensure exchange of expertise across partners with more and less experience and capacity, as was concluded in the TPEA project. Cross-border initiatives outside Europe, such as the Coral Triangle Initiative on Coral Reefs, Fisheries and Food Security (CTI-CFF), have used reciprocal technical capacity building which increased cooperation and trust between institutions, partners and stakeholders [45].

Cross-border MSP projects should go beyond joint knowledge gathering and fact finding to consider providing the capacity for joint actions through shared responsibilities and coownership between actors in the MSP process. Experience from the MAPNOSE project shows that shared responsibility is critical in effective transboundary processes. The differences between national interests, governance structures, and procedural obstacles, makes it challenging to turn transboundary approaches into practice. Capacity building efforts especially policies and resources should target creating a conducive environment for MSP implementation where users, authorities, policy makers and industry/investors come to an 
understanding of the governance system, regulations and provide innovative financing for MSP.

\section{Conclusion}

Much progress has been made in building capacity for MSP at all levels from the individual, institutions to international initiatives over the last ten years in Europe. Contributions range from the setting up of competent MSP authorities, increasing capability in marine-focused organisations and associations, bespoke training courses and international initiatives. This paper based on the experience of these initiatives sets out the various competences needed at each stage of the MSP process. However, capacity building at different levels and between actors are faced with various challenges shaped by the transdisciplinary nature and complexity of MSP, the size of tasks, different competence needs and limitations in resources to respond to these challenges. Review of the experience of capacity building initiatives show that MSP theory is ahead of practical applications and there is the need for balance.

MSP is still at a relatively early stage of development and a more proactive effort is required to establish effective capacity at all levels and to evolve the 'discipline' further in practice. Whilst MSP is transdisciplinary there comes a point when, through application, MSP might be considered a discipline in its own right and its practitioners should be referred to as marine spatial planners rather than 'a GIS specialist supporting MSP' or 'fisheries expert focused on MSP'. An MSP 'discipline' and arguably an MSP 'community of practice' is emerging and this paper sets out few ideas that would contribute to that effort in respect of training, institutions and international initiatives.

While capacity building is relevant to a broad range of actors and at different levels, those directing or developing MSP may need to prioritise resources e.g. setting up a dedicated planning function whilst enabling stakeholder engagement rather than proactively building up capacity in many institutions. The breadth of the subject therefore necessitates more and effective partnerships among the various actors and institutions at all levels. It is evident that in the early and subsequent development of MSP in any country or region whether Europe or elsewhere, project and related funding are invaluable. The proactive input of the academic and teaching community is essential but should be complemented by experience from practical MSP development and implementation to inform and refine courses and training. That will improve the chances of providing adequate supply of MSP expertise and 'marine spatial planners' that can deliver MSP in practice and thereby establish a positive feedback loop in building capacity for MSP. 
Whilst complex, MSP remains a practical process to balance marine environmental goals and socio-economic growth. It is important that political commitment exists, policies and funds are specifically earmarked to build more human, institutional and networking capacity and further support the development of MSP.

\section{References}

[1] C. Ehler

Worldwide status and trends of marine/maritime spatial planning

2nd International Conference on Marine/Maritime Spatial Planning. UNESCO, Paris 15 -17 March (2017).Keynote Address

Google Scholar

[2] European Union. Directive 2014/89/EU Establishing a Framework for Maritime Spatial Planning [2014] OJ L 257/135, Official Journal of the European Union

(2014). Available at: http://eur-lex.europa.eu/legalcontent/EN/TXT/PDF/?uri=CELEX:32014L0089\&from=EN, Accessed 6th Feb 2018

Google Scholar

[3] A. Schultz-Zehden. Institutional Capacity Development for MSP

2nd International Conference on Marine/Maritime Spatial Planning. UNESCO, Paris March 15-17, Paris (2017). In presentation. Available at:

https://drive.google.com/file/d/0BzrpDrQRv9AITHlwYTZSWUVNaHM/view, Accessed 6th Feb 2018 Google Scholar

[4] E. Olsen, D. Fluharty, A.H. Hoel, K. Hostens, F. Maes, E. Pecceu. Integration at the round table: marine spatial planning in multi-stakeholder settings

PLoS One, 9 (10) (2014), p. e109964

https://doi.org/10.1371/journal.pone.0109964

CrossRefGoogle Scholar

[5] J. Ansong, E. Gissi, H. Calado

An approach to ecosystem-based management in maritime spatial planning process

Ocean Coast Manag., 141 (2017), pp. 65-81

ArticleDownload PDFView Record in ScopusGoogle Scholar

[6] M.D.A.A. Le Tissier, J.M. Hills

Practitioner training for building capacity in ICZM

Ocean Coast Manag., 53 (2010), pp. 787-795

ArticleDownload PDFView Record in ScopusGoogle Scholar

[7] B. Cicin-Sain, R.W. Knecht, A. Vallega, A. Harakunarak

Education and training in integrated coastal management: lessons from the international arena Ocean Coast Manag., 43 (4-5) (2000), pp. 291-330

ArticleDownload PDFView Record in ScopusGoogle Scholar

[8] P. Gazzola, M. Roe, P. Cowie

Marine spatial planning and terrestrial spatial planning: reflecting on new agendas

Environ. Plan. C Govern. Policy, 33 (5) (2015), pp. 1156-1172 
View Record in ScopusGoogle Scholar

[9] C. Ehler

Final C-SCOPE Conference. Marine Spatial Planning: Connecting the Dots. Poole England (2012)..Available at:

http://www.cscope.eu/_files/final-conference/presentations/Charles_Ehler_-

_Connecting_the_dots.pdf, Accessed 6th Feb 2018.Google Scholar

[10] P.M. Gilliland, D.d'A. Laffoley

Key elements and steps in the process of developing ecosystem-based marine spatial planning Marine Policy 2008, 32 (2008), pp. 787-796

ArticleDownload PDFView Record in ScopusGoogle Scholar

[11] ICES Cooperative Research Report No. 333

R. Cormier, A. Kannen, M. Austen, T. Therriault (Eds.), Multidisciplinary Perspectives in the Use (and Misuse) of Science and Scientific Advice in Marine Spatial Planning (2016)

$64 \mathrm{pp}$

Google Scholar

[12] C. Ehler, F. Douvere

Visions for a Sea Change. Report of the First International Workshop on Marine Spatial Planning. Intergovernmental Oceanographic Commission and Man and the Biosphere Programme

IOC Manual and Guides, 46: ICAM Dossier, 3

UNESCO(English), Paris (2007)

Google Scholar

[13] E. Gissi, J.L.S. de Vivero

Exploring marine spatial planning education: challenges in structuring transdisciplinarity

Mar Policy, 74 (2016), pp. 43-57

ArticleDownload PDFView Record in ScopusGoogle Scholar

[14] R. Kenchington, J. Day

Zoning, a fundamental cornerstone of effective marine spatial planning: lessons learnt from the Great barrier Reef, Australia

15 J Coast Conservat, 271 (2011)

Google Scholar

[15] J. Day

'The Need and Practice of Monitoring, Evaluating and Adapting Marine Planning and Management - Lessons from the Great Barrier Reef' 32 Mar Policy 823

(2008)

Google Scholar

[16]. W. Qiu, P.J.S. Jones

The emerging policy landscape for marine spatial planning in Europe

Mar. Pol., 39 (2013), pp. 182-190

ArticleDownload PDFView Record in ScopusGoogle Scholar

[17] S.K. Paterson, E. Politi, J.O. Ansong, M. Le Tissier 
M. Karydis, D. Kitsiou (Eds.), Framing Marine Spatial Planning: Future Orientation and Innovation as Steps to Success for Global Cooperation and Sustainability in Marine Spatial Planning: Methodologies, Environmental Issues and Current Trends, Nova Science Publishers Inc. (2017)

ISBN: 978-1-53612-170-4

Google Scholar

[18] UNDP/UNDOALOS

Report on the Consultative Meeting on Training in Integrated Management of Coastal and Marine Areas for Sustainable Development, Sassari, Sardinia, Italy, 21-23 June, 1993

United Nations Development Programme and Division for Ocean Affairs, United Nations, New York (1993)

Google Scholar

[19]. P. Morgan, A. Qualman

Institutional and Capacity Development, Results-Based Management and Organizational Performance. Ottawa: Prepared for the Political and Social Policies Division, Policy Branch Canadian International Development Agency (1996)

Google Scholar

[20] M. Floridi, B. Sanz-Corella, S. Verdecchia

The European Union's EDF Programme for ACP Countries. Capitalisation Study on Capacity Building Support Programmes for Non-state Actors under the 9th EDF (2009)

Google Scholar

[21] J. McCann, T. Smythe, G. Fugate, K. Mulvaney, D. Turek

Identifying marine spatial planning gaps, opportunities, and partners: an assessment. Coastal resources centre and Rhode Island sea grant college program. Narragansett, R.I.

(2014)

$60 \mathrm{pp}$

Google Scholar

[22] European Maritime Day

Capacity Development in Maritime Spatial Planning

(2016)

Available at:

https://ec.europa.eu/maritimeaffairs/maritimeday/en/programme-items/capacity-

development-maritime-spatial-planning, Accessed 6th Feb 2018

Google Scholar

[23] Oregon Sea Grant and NOAA West

Knowledge, Capacity, and Needs for Effective Stakeholder Engagement in Marine Planning:

Key Findings from a West Coast Assessment

Oregon State University (2013)

Google Scholar

[24] J. McCann

Lessons learn from the practice of Marine Spatial Planning: teaching case studies 
Prepared by the Coastal Resources Centre and Rhode Island Sea Grant College Program University of Rhode Island Graduate Scholl of Oceanography. Case Studies of Marine Spatial Planning, Report Series. Available online at:

http://www.crc.uri.edu/download/MSPcurricula_COMPLETEFINAL.pdf (2016), Accessed 6th Feb 2018

Google Scholar

[25] IOC UNESCO \& DG MARE

Joint Roadmap to Accelerate Maritime/Marine Spatial Planning Processes Worldwide (MSP) (2017)

Available online at:http://www.unesco.org/new/en/media-services/singleview/news/mapping_priorities_and_actions_for_maritimemarine_spatial_p/

Google Scholar

[26] Marine Management Organisation

What is marine planning? 3:21 m

Available online at:

https://www.youtube.com/watch?v=cFn0buPVU6A\&t=6s (2013), Accessed 5th Feb 2018

Google Scholar

[27] C. Ehler, F. Douvere

Marine Spatial Planning: a Step-by-step Approach toward Ecosystem-Based Management Intergovernmental Oceanographic Commission and Man and the Biosphere Programme

IOC Manual and Guides no. 53, ICAM Dossier no. 6

UNESCO. (English), Paris (2009)

Google Scholar

[28]. C. Ehler

A Guide to Evaluating Marine Spatial Plans, Paris, UNESCO, IOC Manuals and Guides, 70; ICAM Dossier

(2014)

Google Scholar

[29] WWF

Become a Maritime Spatialist within 10 Minutes - Maritime Spatial Planning in the Baltic Sea (2010)

Available online at:

http://wwf.panda.org/?209330/Become-a-maritime-specialist-within-10-minutes---MaritimeSpatial-Planning-in-the-Baltic-Sea, Accessed 6th Feb 2018

Google Scholar

[30] WWF

How to Safeguard the Seas with Ecosystem-Based Management

(2016). Available online at:

http://wwf.panda.org/what_we_do/where_we_work/baltic/publications/?263750/How\%2Dto

$\% 2$ Dsafeguard\%2Dthe\%2Dseas\%2Dwith\%2Decosystem\%2Dbased\%2Dmanagement\#,

Accessed 6th Feb 2018

Google Scholar

[31] G. Grosseck 
To use or not to use web 2.0 in higher education?

Procedia Social Behav Sci, 1 (2009), pp. 478-482

ArticleDownload PDFView Record in ScopusGoogle Scholar

[32]EU MSP Platform

Overview of Number of MSP Authorities \& Plans per Country

(2018)

Available at:

http://msp-platform.eu/countries-overview

Google Scholar

[33] Federal Maritime and Hydrographic Agency [Bundesamt für Seeschifffahrt und

Hydrographie, BSH]

Spatial Planning in German EEZ

(2017)

Available at:

http://www.bsh.de/en/Marine_uses/Spatial_Planning_in_the_German_EEZ/index.jsp,

Accessed 6th Feb 2018

Google Scholar

[34] Department of Housing, Planning and Local Government

Towards a Marine Spatial Plan for Ireland. A Roadmap for the Delivery of the National Marine Spatial Plan

(2017)

Google Scholar

[35] The Dutch Ministry of Infrastructure and the Environment/Ministry of Economic Affairs Policy Document on the North Sea 2016-2021

(2015)

Google Scholar

[36]. Scottish Government

The marine (Scotland) Act 2010. Part 3

Mar Plann (2010), pp. 5-19

View Record in ScopusGoogle Scholar

[37]. Defra

A Sea Change - A Marine Bill White Paper Consultation - March to June 2007 (2007)

Google Scholar

[38] Marine and Coastal Access Act (2009)

Available at:

http://www.legislation.gov.uk/ukpga/2009/23/contents, Accessed 6th Feb 2018

Google Scholar

[39] European Atlas of the Sea

Maritime Spatial Planning Projects

(2017). Available at: 
http://ec.europa.eu/maritimeaffairs/atlas/maritime_atlas/\#lang $=\mathrm{EN} ; \mathrm{p}=\mathrm{w} ; \mathrm{bkgd}=5 ;$ theme $=2: 0.7$ 5

Google Scholar

[40] H. Backer, M. Frias (Eds.), Planning the Bothnian Sea -key Findings of the Plan Bothnia Project. Digital Edition, Helsinki Commission, Helsinki (2013)

ISBN 978-952-67207-4-8

Google Scholar

[41] M. Pastoors, S. Hommes, F. Maes, D. Goldsborough, B. Vos, M. Stuiver, V. Stelzenmüller, et al.

Preparatory Action on Maritime Spatial Planning in the North Sea - MASPNOSE

(2012)

Google Scholar

[42] A. Barbanti, P. Campostrini, F. Musco, et al.

Developing a Maritime Spatial Plan for the Adriatic-Ionian Region

CNR-ISMAR, Venice, Italy (2015)

Google Scholar

[43] S. Jay, F.L. Alves, C. O'Mahony, M. Gomez, A. Rooney, M. Almodovar, A. Campos

Transboundary dimensions of marine spatial planning: fostering inter-jurisdictional relations and governance

Mar. Pol., 65 (2016), pp. 85-96, 10.1016/j.marpol.2015.12.025

ArticleDownload PDFView Record in ScopusGoogle Scholar

[44] Baltic University Programme

Maritime Spatial Planning: First Planning Meeting on a Masters' Level Education (2012)

Available at:

http://www2.balticuniv.uu.se/index.php/events-list/details/13-maritime-spatial-

planning\#conference-materials, Accessed 6th Feb 2018

Google Scholar

[45] G. Carneiro, H. Thomas, S. Olsen, D. Benzaken, S. Fletcher, S.M. Roldán, D. StanwellSmith, D. Bloxsom, A. Fakhry, Q. Fang, I. Lutchman, M. Tierney, J. McCann, E. Molenaar, A. White, L. Whitford

Study on International Best Practices for Cross-Border Maritime Spatial Planning (2017)

EASME/EMFF/2014/1.3.1.8/SI2.714082

Google Scholar 